\title{
Brand personality: theory and dimensionality
}

Article

Accepted Version

Davies, G., Rojas-Mendez, J., Whelan, S., Mete, M. and Loo, T. (2018) Brand personality: theory and dimensionality. Journal of Product \& Brand Management, 27 (2). pp. 115-127. ISSN 1061-0421 doi: https://doi.org/10.1108/JPBM-06-2017-1499 Available at https://centaur.reading.ac.uk/88534/

It is advisable to refer to the publisher's version if you intend to cite from the work. See Guidance on citing.

Published version at: https://www.emerald.com/insight/content/doi/10.1108/JPBM-06-2017-1499/full/html To link to this article DOI: http://dx.doi.org/10.1108/JPBM-06-2017-1499

Publisher: Emerald

All outputs in CentAUR are protected by Intellectual Property Rights law, including copyright law. Copyright and IPR is retained by the creators or other copyright holders. Terms and conditions for use of this material are defined in the End User Agreement.

\section{www.reading.ac.uk/centaur}

\section{CentAUR}

Central Archive at the University of Reading

Reading's research outputs online 


\section{Brand Personality: Theory and Dimensionality}

\section{Structured Abstract}

Purpose: To critique human personality as theory underpinning brand personality. To propose instead theory from human perception and, by doing so, to identify universally relevant dimensions.

Design/Method: A review of published measures of brand personality, a re-analysis of two existing data bases and the analysis of one new database are used to argue and test for the dimensions derived from perception theory.

Findings: Existing work on brand personality suggests 16 separate dimensions for the construct but some appear common to most measures. When non-orthogonal rotation is used to reanalyse existing trait data on brand personality, three dimensions derived from signalling and associated theory can emerge: Sincerity (e.g. warm, friendly, agreeable), Competence (e.g. competent, effective, efficient) and Status (e.g. prestigious, elegant, sophisticated). The first two are common to most measures, status is not.

Research Implications: Three dimensions derived from signalling and associated theory are proposed as generic, relevant to all contexts and cultures. They can be supplemented by context relevant dimensions.

Practical Implications: Measures of these three dimensions should be included in all measures of brand personality.

Originality: Prior work on brand personality has focussed on identifying apparently new dimensions for the construct. While most work is not theoretically based, some have argued for the relevance of human personality. That model is challenged and an alternative approach to both theory and analysis is proposed and successfully tested.

Keywords: Brand personality; signalling theory; stereotype content model; brand image. 


\section{Brand Personality: Theory and Dimensionality}

The measurement of intangible brand associations is often operationalised using measures of brand personality and while the approach has proven useful to both academics and practitioners in explaining the consequences of such associations with a brand (Eisend and Stokburger-Sauer, 2013), it has attracted controversy. In our paper, we focus on two related issues that have emerged since the first formal publication of a brand personality scale (Aaker, 1997): the theoretical foundations for the construct; and the overly large number of dimensions being discovered. Our main aim is to identify those dimensions of brand personality that can be regarded as truly generic, applicable across all contexts.

Our paper has two main empirical components. The first analysis shows that a large number of 'new' dimensions are being identified in the literature but that many of these contain measurement items which are similar to those used in previous scales to identify dimensions which were given different labels. We then show how a more theoretically based, less empirically driven, approach could have identified three dimensions, (Sincerity, Competence, and Status) two of which are common to most existing measures. We demonstrate how Status could have been identified in two other studies, particularly if non-orthogonal data rotation had been used. We confirm the relevance of these three dimensions in one further study.

In our theory sections, we critique the idea that human personality offers a convincing theoretical basis for brand personality and propose instead the relevance of signalling theory and the stereotype content model.

Being clear as to the theoretical underpinning for brand personality is important because such theory will define the construct and its dimensionality. If human personality is not directly 
relevant to brand personality (as we will argue and evidence) then the assumption that it is will lead to both miss-identification of the construct and its dimensions.

We do not aim to present a new measure of brand personality, rather our main intended contribution is that certain theoretically derived and empirically supported dimensions should be seen as relevant to brand personality irrespective of context and the choice of measurement items. Other dimensions identified in the literature should be used in specific contexts. Our main practical contribution is to propose a model of brand personality where there are a limited number of core dimensions, which theory suggests are universally relevant, but with a larger number of dimensions which may be relevant depending upon the context (brand type, respondent type, and language).

\section{The Evolution of Brand Personality Measures}

Quantitative academic research to measure what was originally labelled as 'corporate personality' began with a semantic differential scale, using items such as ‘irresponsible/responsible' and 'modest/brash' (Markham, 1972). The same projective approach was widely used by practitioners to evaluate product brands; King (1973) for example claiming the difference between competing brands lay in their different 'personalities'. Two other practitioners, Alt and Griggs (1988), published the first scale where there was an emphasis on the dimensionality of the construct.

Aaker's (1997) paper, which more formally identified the dimensions of brand personality, marked a step change in interest in the topic by presenting a rigorously tested, multidimensional measure. The construct was defined as 'the set of human characteristics associated with a brand' a definition we adopt throughout our paper. The measurement scale 
was designed to be generic, applicable to all brands. The five dimensions that emerged from a factor analysis of data from members of the American public asked to assess a number of consumer brands, were labelled as (with example measurement traits in parentheses): Sincerity (honest, genuine, cheerful); Excitement (daring, imaginative, up-to-date); Competence (reliable, dependable, efficient); Sophistication (glamorous, charming, romantic) and Ruggedness (tough, strong, rugged). The well-known and established brands that were used in the survey included some that are both product and corporate brands. As a generic measure, it would remove much of the need for researchers to undertake initial, qualitative work to establish the dimensions and traits needed to explore and measure any brand's intangible associations. However, the dimensional structure had emerged from a factor analysis of the survey data and was not based upon any underpinning theory.

Subsequent work by the same author found that only four of the original five dimensions were relevant in a Japanese context (Sincerity, Excitement, Competence, and Sophistication). 'Peacefulness' in Japan and 'Ruggedness' in America, were argued to be culturally specific dimensions (Aaker, et al., 2001). Similarly, data from Spain yielded dimensions common to both Spain and the United States (Sincerity, Excitement, and Sophistication), and again more apparently country specific dimensions; in Spain (labelled Passion and Peacefulness) and in America (Competence and Ruggedness). Only three dimensions (Sincerity, Excitement, and Sophistication) were common to the studies in Japan, Spain and the USA, and therefore potentially universally relevant and generic (Aaker, et al., 2001). Similar findings were to follow. Sung and Tinkham (2005) supplemented Aaker's scale items with ones that had emerged from initial, qualitative work and found differences in both factor structure and item relevance between their American and Korean data. Muniz and Marchetti (2012) found some dimensions of the Aaker scale were replicated in their study in Brazil, but not all. 
Meanwhile, interest in applying the idea of brand personality measurement was widening beyond the context of customers to include other stakeholders and specifically employees and potential employees. Within the organisational behaviour literature Slaughter, et al. (2004) devised a measure relevant to potential employees. Within the reputation literature Davies, et al. (2004) published a scale validated for both employees and customers. The dimensions of each scale differed from those in Aaker (1997) both in terms of the dimensions identified and the items used to measure individual dimensions.

The setting for the use of brand personification broadened further with its application in location studies, and specifically to the marketing of cities, regions, and countries (O’Shaughnessy and O’Shaughnessy, 2000; Ekinci and Hosany, 2006; Murphy, et al., 2007; Kim and Lehto, 2013). Locations and even countries are personified in common parlance in much the same way as any brand (d'Astous and Boujbel, 2007). Issues of item or dimensional validity emerged which were similar to those raised previously in work with product, service and corporate brands. Ekinci and Hosany (2006) and Murphy, et al. (2007) found that Aaker's brand personality scale did not fully represent the gamut of personality traits associated with destinations and that many traits were located under different dimensions from those in the original scale. The former authors argued that this is due to the same trait item having different meanings when associated with different objects. RojasMendez, Murphy, and Papadopoulos (2013: 1029) suggested Aaker's measure may not adequately represent location personality. Not surprisingly scales have been developed specifically for: country/nation brand personality (d'Astous and Boujbel, 2007; RojasMendez and Papadopoulos, 2012; Rojas-Mendez, et al.2013a); and city brand personality (Kaplan, et al., 2010). 
Brand personality scales have also been developed within a number of other specific contexts, for example for retailers (d'Astous and Levesque, 2003), not for profit organisations (Venable et al., 2007) and universities (Rauschnabel et al., 2016). As the number of published scales has increased, as we will evidence, so have the number of dimensions for what should be the same construct. Brand personality measures have also continued to evolve in the commercial environment. WPP's BrandZ, for example, uses a 24-item personality scale to study the brand imagery of over 14,000 brands worldwide. The scale's dimensions have been labelled as extroversion, sensitivity, playfulness, stability, conscientiousness, and intellectualism (Page and Farr, 2000), labels which appear closer to those of human personality, albeit with 6 dimensions.

Brand personality scales have been criticised for a perceived lack of a clear theoretical underpinning (Austin, et al., 2003; Berens and van Riel, 2004; Clardy, 2012) and because many measurement items (such as masculine and feminine) do not reflect 'personality' (Azoulay and Kapferer, 2003). However, human personality has often been argued to be 'theory' relevant to brand personality. We now review and critique this perspective.

\section{Human personality as the theoretical basis for brand personality}

While Aaker (1997) drew parallels with human personality measures, she did not explicitly link the structure of brand personality with that of human personality, defining the construct of brand personality in terms of the 'human characteristics' that can be associated with a brand, that in her case included gender, which is not a personality trait.. Others have argued that measures designed for human personality can be used or adapted to measure brand personality (Kassarjian, 1971; Huang, et al. , 2012; Kang, Bennett and Peachey, 2016) but 
Caprara, et al. (2001) maintain that there are fundamental differences between the two structures. Nevertheless, Geuens, et al. (2009) aimed to make the dimensions of their brand personality scale compatible with those of human personality, arguing that there is evidence from the structure of published measures to support this. Others imply such a theory base in their work (Chen and Rodgers, 2006; Kaplan et al., 2010; Milas and Mlaĉić, 2007).

There are a number of approaches to the study and measurement of human personality. The one referenced in prior work on brand personality is the Five Factor Model, commonly referred to as the Big 5 (Aaker, 1997; Chen and Rodgers, 2006; Geuens, et al. , 2009; Kaplan et al., 2010; Milas and Mlaĉić, 2007). The dimensions of human personality and typical examples of the traits used to measure them (from McCrae and John, 1992) are:

Extraversion: active, assertive, energetic, enthusiastic, outgoing, talkative Agreeableness: appreciative, forgiving, generous, kind, sympathetic, trusting Conscientiousness: efficient, organised, planful, reliable, responsible, thorough Neuroticism: anxious, self-pitying, tense, touchy, unstable, worrying Openness: artistic, curious, imaginative, insightful, original, wide-interests This and other similar personality measures were derived as self-reports with measurement items for human Agreeableness such as 'Most people I deal with are honest, trustworthy' and 'My first reaction is to trust people' (both taken from the NEO PIR) ${ }^{1}$, whereas brand personality measures are by definition 'other' reports which ask respondents, for example, 'If brand $\mathrm{x}$ came to life as a human being would s/he be trustworthy?' to measure the apparently corresponding dimension of brand personality, Sincerity. Furthermore, the human inventory

\footnotetext{
${ }^{1}$ http://www.hogrefe.co.uk/news/wp-content/uploads/2015/06/NEO-PI-R_Technical.pdf
} 
for Agreeableness measures the propensity of the individual to trust, whereas the brand inventory for Sincerity measures whether the brand is trusted, which are quite different and not directly comparable. A high score for being an Agreeable human implies the individual is overly predisposed to trust (a negative) while being highly trusted is an objective for any brand.

Aaker et al. (2001) acknowledge that only three dimensions in the original scale (Aaker, 1997) are comparable with those in the "Big 5" (Sincerity with Agreeableness; Competence with Conscientiousness and Excitement with Extraversion). Slaughter et al. (2004) concur and note that the two other dimensions in Aaker's measure (Sophistication and Ruggedness) differ markedly from Neuroticism and Openness in human personality, even when the antonyms of their measurement items are considered.

The idea that the structure of human personality offers a theoretical framework for brand personality can be challenged more fundamentally, as the Big 5 framework of human personality was itself empirically derived, with little or no theoretical support to guide its development. Early work relied upon factor analysis of survey data using words taken from the English dictionary that appeared relevant to human traits, rather than any theory as to what the dimensions of personality might be (McCrae and John 1992:103). Digman (1990) recalls the use of the term 'taxonomy', rather than 'theoretical structure' or similar, in labelling the emergence of five robust factors. Two of its greatest proponents, McCrae and John (1992:189) explain that 'the Big Five taxonomy provides descriptive concepts that still need to be explicated theoretically'. The word theory means: 'a supposition or a system of ideas intended to explain something, especially one based on general principles independent of the thing to be explained,' and the Big 5 taxonomy was not and is still not, a theory, as it is 
not independent of what it is designed to explain, as it was derived from the analysis of personality traits. The emergence of the Big 5 did, however, provide researchers with a common language and 5 replicable domains of personality, facilitating comparisons between studies.

Interestingly, similar issues to those we noted earlier with brand personality had also emerged in human personality research, specifically around the validity of the Big 5 in different cultures (McCrae and Costa, 1997; McCrae and Allik, 2002). There is also an ongoing debate as to the appropriate number of dimensions for human personality, (Musek, 2007; Ashton, et al., 2009).

There are two further difficulties in seeing brand personality as being directly associated with human personality. First, if asking respondents to evaluate a brand's image through personification involves, as some contend (e.g. Cohen, 2014), their thinking of an actual person, then their thought processes should be similar to those when asking someone to evaluate the personality of an actual human. However, when neural magnetic resonance imaging was used to compare how respondents processed human personality and brand personality data (Yoon, et al., 2006) the data were found to be processed in different parts of the brain, leading to a conclusion from the authors that their results 'challenge the view that processing of products and brands is akin to that of humans' (Yoon, et al., 2006:31).

Second, as both human and brand personality are measures of reputation, the first of a person if viewed by another (Hogan and Hogan, 2007: 8), the second of a brand (Davies et al., 2001), it would be very surprising if they had nothing in common, given that they share a basis in spoken language. But is there enough evidence to support the idea that human 
personality is relevant to brand personality? The direct implications of adopting the Big 5 dimensions of human personality as theory for brand personality are that the dimensions should be the same (Geuens, et al. , 2009) and that humanistic associations other than those which can be regarded as personality traits should be excluded from such measures (Azoulay and Kapferer, 2003).

We now discuss the relevance of signalling theory and the Stereotype content model (SCM) as an alternative and competing theoretical underpinning for brand personality.

\section{Human Communication and Perception Theory and Brand Personality}

A signal is defined as "an action that the seller can take to convey information credibly about any unobservable product quality to the buyer" (Rao, et al., 1999: 259). Signalling theory explains that, in a context of information asymmetry, the knowledge holder (here the company owning the brand) may not wish to provide the other party (here the actual or potential customer, employee or other stakeholder) with perfect information, and instead uses one or more signals to communicate (Spence, 1973). A signal is proxy information; for example, employers accept qualifications as a signal of intelligence and employees use their qualifications to signal the same attribute (Spence, 1973). Signalling works firstly when members of a group (here competing brands) vary in some underlying attribute (here the qualities of their brands) that is difficult or impossible to observe, but which could be reliably signalled and, secondly, when recipients (e.g. customers) stand to gain from such information (BliegeBird and Smith, 2005).

Specific signals evolve because senders learn what information it is useful to convey; additionally, the more costly the signal, the more reliable the signal is perceived to be 
(Connelly, et al., 2011). A brand's advertising is a costly signal used to signal objective information such as product efficacy but also more perceptual and symbolic attributes (Erdem and Swait, 1998: 137) such as the brand's personality. Specific signals by corporates have been noted which map onto those of individual dimensions of brand personality: that of corporate competence and, by implication, the competence and reliability of a company's products (Fombrun and Shanley, 1990); and that of the company's credibility (Erdem and Swait, 1998) and trustworthiness (Wang, et al., 2004). The last two mentioned reflect the brand personality dimension of Sincerity and both credibility and prestige as signals in the marketing of brands (Baek et al., 2010).

Humans also use signalling. For example, males give higher tips than females, particularly when in female company, signalling altruism and generosity (Iredale, et al., 2008). Human to human signals indicating honesty (Zahavi, 1977) and competence (Spence 1973) map onto brand personality dimensions but one commonly mentioned signal, status (Fehr and Fischbacher, 2003; Griskevicius, et al., 2007; Nelissen and Meijers, 2011) is, as we shall show, rarely specifically identified in brand personality measures. Many brands signal status and their display promotes a competent impression to others and can also induce positive behavior among them (Griskevicius, et al., 2007). Firms, in turn, will have learnt that their brands should signal such traits and to avoid providing information which may lead to negative judgements on these same dimensions.

Signalling theory is compatible with the idea that brand meaning is co-created between firm and customer (Wallpach et al., 2017) in that it emphasises that companies learn from how customers react and which signals they should deploy in their marketing. But signalling theory does not overtly extend to identifying a typology of signals. An explanation for three 
common types of signal (honesty/sincerity, competence, and status) can be found however in a theory which aims to explain which signals humans seek and why- the stereotype content model (SCM). This argues that we judge social groups or individuals in terms of their relative 'warmth' and 'competence' (Fiske, et al., 2002). Warmth judgements concern the perceived intentions of another party, specifically how friendly, helpful and trustworthy they are thought to be (Fiske, et al., 2007), while competence concerns the ability of that other party to enact their intentions. It is also argued that someone's social status is used to infer their competence, as we assume that people acquire status by being competent (Fiske, et al., 2007) and also that low status groups are seen as such because they are seen as lacking both competence and warmth (Cuddy, et al., 2008). In other words, the three aspects are not independent of each other.

The need to judge warmth and competence is claimed to be primeval, dating from a time when a failure to make such judgements correctly risked personal harm, such that only those genetically predisposed to make them survived (Fiske, et al, 2007; Krings, et al., 2011) thus ensuring that modern humans still automatically make such evaluations. Such judgements are of human traits, and the dimensions of warmth and competence are very similar to those of two of the dimensions used to measure brand personality (Sincerity and Competence) and can apply to both individuals and groups. The SCM has subsequently been used to explain differences in how both organisations and countries are perceived (Aaker, et al., 2010; Cuddy et al., 2009) emphasising the humanistic associations we make with both, and formally adapted to the context of branded entities (Kervyn, et al., 2012).

While warmth (labelled as Sincerity in Aaker, 1997) and competence are commonly identified in brand personality measures, status has not been overtly identified until relatively 
recently as a specific dimension in brand personality as 'prestige' (Rauschnabel, et al., 2016). Status is certainly relevant to brands and to their acquisition. Status symbols have also changed from the mere possession of something that is rare such as a car or a television in the early part of the last century (Blumberg, 1974) to today when what matters is the brand of car or television that is owned. Many brands are bought to signal status (Eastman, et al., 1999; Han, et al., 2010). The status or prestige of one's employer is just as relevant. For example working in the civil service, rather than in commerce, is seen as less prestigious by potential employees (Vandenabeele, et al., 2004). Existing employees are also concerned about how the status of their employing organisation is perceived externally; 'perceived external prestige' influences both employee identification (Smidts, et al., 2001) and commitment (Carmeli, 2005).

Despite the importance of status being seen to have evolutionary explanations (Turke and Betzig, 1985; Cheng, et al., 2010) signaling and stereotype content theories differ in their location of status. We return to this issue later but note for the moment that if these dimensions are not independent, as implied by the SCM, it would be inappropriate to use orthogonal rotation to explore and factor data pools to identify them, as such an approach assumes each dimension is independent of and uncorrelated with others.

The idea that there are a limited number of theoretically supported dimensions of brand personality suggests that these might emerge irrespective of context. To explore this further, we first compare the dimensions found in published scales of brand personality by comparing the measurement items used to define them.

\section{Divergence and convergence in brand personality measures}


Table (1) shows the dimensions and typical items identified in 21 studies published between 1997 and 2016 and derived in various contexts of: respondent type (customer, consumer, student, commercial buyers and sellers, employees and potential employees); branded entity type (consumer brands, company/corporate brands, cities and countries) and country/culture (USA, UK, Spain, Japan, Holland, Canada, Germany, Croatia, Turkey, India, Brazil, Belgium and China $^{2}$ ). We included any study identified in our literature searches where the objective had been to derive a brand personality scale and where the work had been published in a refereed publication.

Two coders (one not involved in this paper) were asked, independently, to identify any commonality between dimensions identified in separate studies by comparing the measurement items used to identify each dimension (not the dimension labels) starting with the 5 dimensions of Aaker (1997). Each scale was considered in the same order by each coder. They used dictionaries of synonyms and antonyms to decide whether the items for a given dimension in each subsequent paper were similar in meaning to those describing a dimension in a previous paper. The coders then compared their analyses, identifying where they agreed and whether an agreement could be reached where differences occurred. There were 90 coding decisions to make and the initial comparison showed agreement on 87 (97\%). After discussion, this rose to 89 (99\%). Table 1 shows where an agreement was reached on dimension similarity and uses a question mark where coders agreed they could not be sure about the allocation or the one case where one felt sure and the other did not.

Take in Table 1 here

\footnotetext{
2 The scale for the Geuens et al 2009 study was derived in Belgium and tested in 9 other, mainly European countries)
} 
The protocol adopted for Table 1 was to use the label for a dimension from the first paper considered and then to allocate the dimensions identified in other work, if possible, to one of these same labels. For example Aaker (1997) used the label of Sincerity for a dimension including items such as honest, genuine and cheerful, while Davies, et al. (2004) and Slaughter, et al. (2004) referred to similar dimensions as Agreeableness and Boy Scout respectively, but had used items with similar meaning to define them. Consequently, Sincerity is shown in Table 1 as a dimension common to all three studies.

Using this approach, the dimension Sincerity (honest, genuine and cheerful) was found in all but 2 of the 21 studies, Competence (reliable, dependable, efficient) in all but 5, Excitement (daring, imaginative, up-to-date) in all but 1, and Sophistication (glamorous, charming, romantic) in all but 8 . Thereafter there is little commonality of dimensions, with Ruggedness (tough, strong, rugged) being identifiable in a maximum of only 6 studies, Ruthlessness (controlling, aggressive) in at most 6 and Peacefulness (gentle, mild, peaceful) in just 5 . Some dimensions emerged in only a single study.

The number of separate dimensions for brand personality implied by Table 1 is 16 , which is far too large a number to be useful as a 'generic' measure. However, what is notable is how much the 21 scales share in terms of their dimensionality, irrespective of the sometimes different contexts and languages in which they were developed (and the differences in the specific items used to measure a particular dimension). Despite the differences in labels given to similar dimensions by authors, some dimensions appear common to most contexts, even though the items to measure them might differ, indeed need to differ, with context. Competence for example, rather than being specific to an American culture (Aaker, et al., 2001) and to consumer evaluations of product brands, is clearly relevant in many contexts: 
different cultures, brand types (corporate, country etc.) and respondent types (customer, employee, potential employee).

While some studies made specific reference to human personality as a theoretical framework, most made no explicit reference to any theoretical underpinning and very few compared the dimensionality of their measures with that of human personality. Only two studies appeared to have begun their empirical work by nominating the dimensions they expected from theory and then trying to populate them with relevant items, in other words almost all work was empirically driven. Only 5 studies reported on the predictive validity of their measures. 8 studies reported incorporating the items from Aaker (1997) and adding to them from either qualitative work or from other existing scales.

There were differences in how authors defined brand personality and while 12 used Aaker's definition (humanistic associations) or an adaption thereof, two papers used 'a mental representation of a store that typically captures an individual's personality' and three used 'brand personality is the set of human personality traits that are both applicable to and relevant for brand'. The difference is that Aaker's original definition encompasses the broader idea of the human characteristics associated with a brand (which might include gender for example) while some others emphasise the specific construct of personality i.e. just behavioural traits. The former definition allows the inclusion of measurement items that are not behavioural traits (hence the critique that Aaker's measure is not a measure of 'personality' and should be called something else (Azoulay and Kapferer, 2003)). However, this criticism would be more convincing if any dimension of brand personality was dominated by measurement items that are not behavioural traits and none can be argued to be so. 
In summary, the data show that 4 dimensions are commonly identified across contexts: Sincerity (honest, genuine and cheerful), Competence (reliable, dependable, efficient), Excitement (daring, imaginative, up-to-date) and Sophistication (glamorous, charming, romantic). The first two are compatible with the dimensions emphasised in both signalling theory and the SCM, while the last two are not. One barrier to concluding that this evidences universality is that many researchers included the items identified in prior work within their item pool, making the emergence of similar dimensions in their own work more likely than if the item pool had been generated solely within their own work. However, the more fundamental problem is that few authors had started with dimensions defined from theory, then populated the measure with relevant items, as is advised for scale development (Churchill, 1979). One exception was the work of Geuens et al. (2009) who aimed to match their scale to the Big 5 structure and to include only traits in their measure. However the 5 dimensions they identify are still not well aligned to those of the Big 5 and contain very few (2 or 3) measurement items for each dimension, some of which ('ordinary' and 'simple') are not behavioural traits. Prestige or Status was only identifiable in 3 studies, although the coders noted that the two dimensions of Excitement and Sophistication contained elements of what might have formed a single dimension of that name. For example, Aaker (1997) includes the item 'upper class' in the dimension labelled as Sophistication, Davies et al. (2004) include 'prestigious and elitist' as items in their similar dimension, labelled as Chic. Both scales include the items 'cool' and 'trendy' in their dimensions labelled respectively as Excitement and Enterprise.

17 of the 21 studies reported using the orthogonal rotation of their survey data to identify individual dimensions (two used non-orthogonal rotation and two did not report their rotation 
method), where the implied assumption is that such dimensions are not correlated. On reflection, it is surprising that orthogonal rotation has been used in most prior work (and without any discussion as to why). Natural phenomena are rarely uncorrelated; leading to the recommendation that non-orthogonal rotation should be the preferred approach in the social sciences, even though this can make identifying factors more difficult (Osborne and Costello, 2009). Given that prior work on human perception had suggested that status, competence and warmth/sincerity are correlated, we explored what happens when the same databases are analysed using non-orthogonal rotation and where the analysis is seeded with key items from theoretically defined dimensions.

\section{Testing an Alternative Theoretical Basis for Brand Personality}

Rauschnabel et al. (2016) identify 6 dimensions for University brand personality including Prestige (leading, reputable, successful), Sincerity (helpful, trustworthy fair) and Conscientiousness (competent, organised, effective). Their measure labelled as 'prestige' is compatible with the idea of status and 'conscientiousness' with competence. Their factor analysis approach was based on non-orthogonal rotation. They show that, while each of their dimensions correlated with one another, that each makes a significant contribution to the prediction of one or more of three outcomes- brand love, alumni support and word of mouth.

We now test the idea that three similar, correlated factors (warmth, competence, and status) could have been identified if non-orthogonal rotation had been used by reanalysing two large data sets. We obtained access to the data of Davies et al. (2004), n=4626 and where 93 items (including the items "warm, competent and prestigious") were used to assess the brand personality of 15 corporate brands by customers and employees and that of Rojas-Mendez, et 
al. (2013b) where the items 'warm, competent and fashionable' were included among an item pool of 209 used in the assessment of 3 countries ( $n=3607)$. In neither case was a dimension that could be labelled as status specifically identified in the original analysis. In both cases orthogonal rotation had been used and the dimensions had been defined empirically.

The data for corporate brands (from Davies et al., 2004) were first re-analysed by imposing a three factor solution under non-orthogonal rotation (using direct oblimin with a delta value of -.4). Following Churchill (1979) we purified the trait list by eliminating those whose loadings in the pattern matrix fell below $.4, .5$ and finally .6 on each factor. At each stage three marker traits (warm, competent, and prestigious) were retained to seed the analysis. The items retained are shown below. Dimension 1 contains mostly items from the dimension labelled as Competence in Table 1, and is compatible with the dimension of the same name in both the SCM and in signalling theory. Dimension 2 contains items previously associated with Sincerity with the addition of one item from the dimension the original scale's authors had labelled as Ruthlessness (but negatively valenced), items compatible with warmth from the SCM and with trustworthiness from signalling theory.

$\begin{array}{lll}\begin{array}{l}\text { Dimension 1: } \\ \text { Competence }\end{array} & \begin{array}{l}\text { Dimension 2: } \\ \text { Sincerity }\end{array} & \begin{array}{l}\text { Dimension 3: } \\ \text { Status }\end{array} \\ \text { Confident } & \text { Cheerful } & \text { Sophisticated } \\ \text { Ambitious } & \text { Warm } & \text { Exclusive } \\ \text { Competent } & \text { Open } & \text { Prestigious } \\ \text { Leading } & \text { Supportive } & \text { Refined } \\ \text { Professional } & \text { (Arrogant) } & \text { Glamorous } \\ \text { Hardworking } & \text { Friendly } & \end{array}$

(To be compatible with the first part of our paper, we label this dimension hereafter as Sincerity, rather than warmth). Dimension 3 contains items originally associated with two dimensions labelled as Enterprise and Sophistication (Table 1), items that indicate a brand's status and a dimension compatible with status and prestige from signalling theory. The three 
dimensions explained $56 \%$ of variance in the dataset. No items were retained from dimensions labelled by the original authors as Informality and Machismo, (which had been under-identified in the original analysis). Cronbach alphas were: status .77; sincerity .82 and competence .85 .

Each of the three factors made a unique contribution to the prediction of satisfaction (a 6 item measure in the same database) in a multiple regression, Competence (beta $=.412, \mathrm{p}<.001$ ), Sincerity (beta=.290, p<.001) and Status (beta=.145, p <.001). Fiske, et al., (2002) imply that, in the context of human to human interaction, status is predicted by a combination of sincerity and competence. The three dimensions from our analysis were significantly correlated, and status could indeed be predicted significantly by competence and sincerity, but the latter could also be predicted by competence and status, and competence in turn by sincerity and status.

To test for the co-existence of similar dimensions in place branding, we re-analysed a database with a total of 3,607 cases obtained from 10 individual surveys of country personality. Data collection had been carried out in seven different countries (China, Puerto Rico, Chile, Saudi Arabia, Canada, Ecuador and Argentina) and in four languages, with three countries used as stimuli, the U.S.A, Canada, and Japan. The starting point was a scale with a total of 209 personality traits specifically applicable to countries (Rojas-Mendez, et al., 2013b). Again following Churchill (1979), we purified the trait list discarding unrelated items. Three items, 'warm', 'competent' and 'sophisticated' were used to seed the factor analysis to test for the three theoretically informed dimensions of warmth, competence and status (the database did not include 'prestigious') and items not loading onto the factors 
defined by the seeding terms first above 0.5 , then 0.6 were eliminated. As before, and to allow the dimensions to correlate, Direct Oblimin was used for data rotation.

The item "competent" was replaced by "efficient" early in the process when it became clear that no coherent factor was emerging and that the former item loaded too heavily on another factor. The items for the three dimensions achieved using a delta of .3 are shown below:

$\begin{array}{lll}\text { Sincerity } & \text { Competence } & \text { Status } \\ \text { Trustworthy } & \text { Enterprising } & \text { Posh } \\ \text { Sincere } & \text { Future oriented } & \text { Sophisticated } \\ \text { Honest } & \text { Competitive } & \text { Fashionable } \\ \text { Caring } & \text { Confident } & \text { Elegant } \\ \text { Warm } & \text { Efficient } & \end{array}$

The alpha values for the three dimensions were: Sincerity .86, Competence .75 and Status .64 , the value for the last being lower than the normally acceptable threshold, despite Status being clearly relevant to place branding. The total variance extracted was $56.4 \%$. The dimensions correlated significantly and again each dimension could be predicted by the other two. Each of the three dimensions made a significant and independent contribution to the prediction of four DV's included in the database (Table 2), purchase intention of items made in the country (4 items); travel intentions to the country (5 items); intention to develop ties with the country (5 items) and overall attitude towards the country (4 items), all measures were taken from Rojas-Méndez, Murphy, and Papadopoulos (2013).

Take in Table 2

In summary, reanalysing the original data from two quite different and independently derived data sets showed support for a somewhat different configuration of dimensions from those originally identified by both groups of original authors. Each dimension this time is grounded in theory as to why humans might evaluate a brand. In both cases, non-orthogonal rotation 
was used allowing the dimensions to co-vary, as implied by the same theory. Two issues remained. First, the branded entities we had considered were well known and prominent. Second, the brands and countries would not necessarily be seen as low in status.

Our final study aimed to consider the three dimensions of sincerity, competence, and status in a different context, that of the employer brand, a context where we could include data on brands with a wide range of status. We also wished to ensure that our data were from a large sample of branded entities and to include more items to populate each dimension than were available in the two existing databases we had re-analysed. 58 items were drawn from prior work to populate the three dimensions of sincerity, competence, and status and 113 respondents were asked to evaluate their employers. Respondents were given 15 types of organisation to select from to describe their employer and no one type was selected by more than 12 respondents, the top three types being telecommunications (12), education (11) and manufacturing (10). As before a three dimensional solution using Direct Oblimin was seeded with three items: warm, competent and prestigious. The most appropriate 5 items were retained in the final solution where the three dimensions explained $72.37 \%$ of the data variance were:

\section{Sincerity}

Warm

Friendly

Pleasant

Agreeable

Cheerful

\section{Competence}

Competent

Efficient

Effective

Confident

Professional

\section{Status}

Prestigious

Refined

Elegant

Sophisticated

Glamorous

The alphas for each dimension were: Sincerity.92, Competence .89 and Status .86. The AVE figures were Sincerity .72, Competence .64 , and Status .55 , each above the 0.5 cut-off recommended by Fornell and Larcker (1981). This time Status was predicted by Sincerity 
$(\mathrm{t}=3.76, \mathrm{p}<.000)$ but not by Competence $(\mathrm{t}=.868, \mathrm{p}=.387)$. High status organisations are then not necessarily such because they are seen as both warm and competent. We tested the relative ability of the three dimensions to predict a number of dependent variables (DV's) included in the survey, satisfaction (4 measurement items taken from Davies et al., 2004), engagement (9 items taken from Soane, et al. (2012) and self-congruence (4 items from Poddar, et al., 2009).

Take in Table 3

For the first two DV's, status did not make a significant, independent contribution in predicting them, but for self-image congruence the contribution from status was significant and as high or higher than that for sincerity and competence (Table 3). Earlier we noted a similar finding in the work of Rauschnabel et al. (2016). Each of the three dimensions is then capable of making a useful and independent contribution to an understanding of relevant outcomes.

\section{Discussion and Conclusions}

\section{The theoretical underpinning for Brand Personality}

Brand personality has been criticised for a lack of theoretical underpinning (Austin, et al., 2003; Berens and van Riel, 2004). Scale development should ideally begin with a theoretically informed understanding of the construct to be measured (Churchill, 1979), and brand personality measures have been, in the main, derived without such underpinning. However human personality has been frequently cited as the theory most relevant to brand personality. We have challenged that view and identified a number of concerns, most notably that the individual dimensions of each construct with similar labels are far from similar in reality and that the Big 5 human personality framework in itself cannot be regarded as a 
theory, as it was derived from the data it is supposed to explain and is therefore not independent of what it is meant to explain.

We propose instead signalling theory (Spence, 1973; Connelly, et al., 2011) as more relevant because it explains how companies come to edit and shape their communication and to signal only specific aspects of a brand, because they find they work for them in the marketplace. Humans, as customers or employees, benefit from such signals as they can use them in constructing or maintaining their own self-image and in promoting that to others. The theory is also independent of the brand personality construct. Work within this perspective identifies a number of signals from companies to the market or between humans that reflect commonly identified, individual dimensions of brand personality including those we have labelled as Sincerity (Erdem and Swait, 1998; Wang, et al., 2004) and Competence (Spence 1973;Fombrun and Shanley, 1990; Griskevicius, 2007). However the same literature often emphasises the signalling of status (Fehr and Fischbacher, 2003 Griskevicius, et al., 2007 Nelissen and Meijers, 2011) and while status is relevant to Aaker's original definition of brand personality (the set of human characteristics associated with a brand) it was not clearly identified in early scale development work.

Signalling theory in itself does not define which signals are most relevant to brands and for this we used a second theory, that of the stereotype content model (Fiske, et al., 2002; 2007) which specifies warmth/sincerity, competence and status as fundamental to humans and which has been extended to corporate and brand imagery (Aaker, et al., 2010; Cuddy, et al., 2009; Kervyn, et al., 2012). 
If brand personality measures had been less empirically driven or had such work started with a theoretically informed understanding of what its dimensionality might be, and/or if nonorthogonal rotation had been used to identify dimensions, then, as we have demonstrated, status might have been more widely recognised.

\section{The Dimensionality of Brand Personality}

Our review of 23 measures of brand personality (Table 1) showed that sincerity and competence are two of the most frequently identified dimensions in prior work, but that status can only be identified in more recent studies and then in contexts where status might be more relevant. The review also showed that ever more dimensions of brand personality are being identified, in total 16 at the time of writing. Both culturally specific (Aaker, et al., 2001; Sung and Tinkham, 2005; Muniz and Marchetti, 2012) and entity specific dimensions can exist (Ekinci and Hosany, 2006; Murphy, et al., 2007). We use this idea to propose that three dimensions, sincerity, competence, and status, be regarded as universally relevant with one or more of the 13 other dimensions from prior work being relevant to a specific context. The model shown in Figure 1 illustrates the structure being proposed.

Take in Figure 1 here

Some previously identified dimensions may be facets of other, higher order dimensions. Our coding exercise identified the possibility that Sophistication and Excitement could be facets of Status. However such thinking does not totally explain the existence of some of the dimensions identified in prior work. Marketers will also find new aspects of brand imagery to differentiate their offerings and many of these will be relevant only to specific markets, cultures or contexts or even time frames. Human personality, as a theory, does not predict a large number of dimensions or predict that further dimensions might emerge. Instead, it identifies five specific dimensions. 


\section{Implications for practice}

Our work has implications for practitioners, not only in how brand imagery might be measured but also in the marketing of branded entities. If, as we argue from theory, individuals automatically assess a brand for its sincerity, competence, and status because of fundamental human needs, then marketers should ensure that they provide signals to their marketplace to position their brands on each dimension. If they fail to do so, potential consumers and employees will inevitably use whatever information they can to evaluate a brand on each dimension.

In comparing prior work to construct Table 1, we learnt to ignore the labels given to individual dimensions and to focus instead on the actual measurement items being reported by authors. When these were compared between papers, it became clear that apparently different dimensions (because they had been labelled differently) were in fact similar. Translating scales into another language can create similar issues if the meaning of the measurement item within its context is not translated. The items chosen to measure each dimension can, indeed should, be chosen to be commensurate with both the branded entities being assessed and the language and culture of respondents. These items can differ, as we evidence, yet still measure the same underlying dimension, something widely recognised in human personality measures, with various scales (the NEO PI-R, the FFMRF, and the $\mathrm{BFI}^{3}$ ) each measuring the same Big 5 dimensions but using different measurement items.

\section{Implications for Further Work}

\footnotetext{
${ }^{3}$ The NEO PI-R is an acronym for the revised version of the Neuroticism-Extraversion-Openness Personality Inventory; the FFMRF for the Five-Factor Model Rating Form; and the BFI for the Big Five Inventory.
} 
In this paper we do not propose a new measure of brand personality, rather we emphasise the relevance, for all such measures, of two commonly identified dimensions (sincerity and competence) and one that is less commonly identified (status), as all three have strong theoretical support. We demonstrate that each can make a unique contribution to explaining a number of dependent variables.

It would be useful then to see whether other, existing data pools used to create personality scales can be re-analysed to identify the dimension of status, although unless the data set contains items comparable with the idea of status, this may prove problematic. Future work on developing brand personality measures should consider including descriptive items or traits that are compatible with the three dimensions of sincerity, competence, and status. There is, we believe, a danger in gathering items that might, purely by chance, identify what might appear to be a new dimension. Alternatively, new dimensions can be based upon theory that is relevant to the context being considered, and/or from preliminary work demonstrating the relevance of the dimension.

A multi-dimensional scale to measure brand imagery is of greater value if individual dimensions contribute uniquely to understanding and explaining the outcomes of successful or unsuccessful brand management. Few of the papers we reviewed included a justification of their measures by demonstrating their potential to predict or explain typical DV's; fewer still that each dimension could make a unique contribution in the presence of other dimensions.

We lack a complete understanding of the antecedents of most brand personality dimensions. While we have used theory to explain why three specific dimensions are relevant to both the marketing and purchasing of brands, and have similarly explained how signalling any 
dimension can become relevant, we have not explained how marketers and consumers come to concur on other dimensions. Work within semiotics emphasises that signs (here we use the word signal) are generated in the producer's discourse about the product but that the consumer evaluates this against a semiotic system (Nöth, 1988) while a co-creationist perspective sees the consumer as more proactive in creating meaning around a brand (von Wallpach, 2017).

Views differ markedly as to whether brand personality is (just) a projective technique used to measure intangible brand imagery (Keller, 1998), in other words, that brand personality and (intangible) brand image are much the same, or whether brand personality and brand image are separate, if related, constructs (Hosany, et al., 2006). A brand personality scale is far from being a qualitative, projective technique (Hofstede, et al., 2007) as it imposes a defined structure on the respondent; one close to asking directly for a response to specific attributes. Compare asking a respondent, as is common in a brand personality questionnaire, "If brand X came to life as a human being, would s/he be trustworthy?" with "How strongly do you agree that brand X is trustworthy?" Are two separate things being measured here or is the device used in the first version of the question merely enabling the respondent to answer the same question? Being seen as trustworthy is a central element of brand image, but can it simultaneously be part of brand personality? A consensus is then needed as to whether brand image defined as the direct measurement of intangible attributes and brand personality are the same or different. Future work should address this question and a good starting point would be to compare the use of a personified measure with its direct equivalent.

Is 'personality' the most appropriate label for the scales we have been discussing or is it getting in the way of progress? Avis, et al. (2012) showed that even rocks, items with questionable humanistic associations, can be assessed and differentiated using a brand 
personality scale. Better still if all such measures could be regarded as those for intangible associations, but ones using a personified approach to questioning.

If a consensus is reached among researchers as to the dimensionality of brand personality, this could have a similarly invigorating impact that the advent of the Big 5 human personality factors made on research into links between human personality and its consequences. But unless there is agreement on what are truly generic dimensions, research using one measure may not be comparable with that using another. It is highly unlikely that agreement will emerge at the level of the measurement items populating individual dimensions, but this is irrelevant as these can, indeed will, need to vary when researching different types of entity and within different contexts, due to the emic and etic issues we have discussed. 


\section{References}

Aaker, J. L. (1997), “ Dimensions of Brand Personality”, Journal of Marketing Research, Vol. 34 No.3, pp. 347-356.

Aaker J. L., Benet-Martinez, V. and Garolera, J. (2001), “Consumption symbols as carriers of culture: A study of Japanese and Spanish Brand Personality constructs”, Journal of Personality and Social Psychology, Vol. 81 No. 3, pp.492-508.

Aaker, J. L., Vohs, K. D. and Mogilner, C. (2010) "Nonprofits are seen as warm and forprofits as competent: Firm stereotypes matter", Journal of Consumer Research, Vol. 37 No.2, pp. 224-237.

Alt, M. and Griggs, S. (1988), “Can a brand be cheeky?”, Marketing Intelligence and Planning, Vol. 6 No. 4, pp.9-16.

Ashton, M. C., Lee, K, Goldberg, L. R. and de Vries, R. E. (2009), "Higher order factors of personality: Do they exist?", Personality and Social Psychology Review, Vol. 13No.2, pp.7991.

d'Astous, A. and Levesque, M. (2003), “A scale for measuring store personality”, Psychology and Marketing, Vol 20 No.5, pp. 455-469.

d'Astous, A. and Boujbel, L. (2007), "Positioning countries on personality dimensions: Scale development and implications for country marketing”, Journal of Business Research, Vol. 60 No.3. pp.231-239.

Austin, J. R., Siguaw, J. A. and Mattila, A. S. (2003), “A re-examination of the generalizability of the Aaker brand personality measurement framework", Journal of Strategic Marketing, Vol. 11 No. 2, pp. 77-92.

Avis, M., Aitken, R. and Ferguson, S. (2012), "Brand relationship and personality theory: metaphor or consumer perceptual reality?", Marketing Theory, Vol. 12 No.3 pp. 311-331. 
Azoulay, A. and Kapferer, J-N. (2003), "Do Brand Personality scales really measure brand personality?", Journal of Brand Management, Vol. 11 No.2, pp. 143-155.

Baek, T. H., Kim, J., and Yu, J. H. (2010), "The differential roles of brand credibility and brand prestige in consumer brand choice", Psychology \& Marketing, Vol. 27 No. 7, pp. 662678.

Berens, G. and van Riel, C. B. M. (2004), "Corporate associations in the academic literature: Three main streams of thought in the reputation measurement literature", Corporate Reputation Review, Vol. 7 No. 2, pp. 161-178.

BliegeBird, R.and Smith, E. (2005). "Signaling theory, strategic interaction, and symbolic capital”, Current Anthropology, Vol. 46 No.2, pp. 221-248.

Blumberg, P. (1974), "The decline and fall of the status symbol: Some thoughts on status in a post-industrial society”, Social Problems, Vol. 21 No. 4, pp. 480-498.

Bosnjak, M., Bochmann, V. and Hufschmidt, T. (2007), "Dimensions of Brand Personality attributions: a person-centric approach in the German cultural context”, Social Behavior and Personality: an International Journal, Vol. 35 No. 3, pp. 303-316.

Caprara, G. V., Barbaranelli, C. and Guido, G (2001) "Brand Personality: How to make the metaphor fit?" Journal of Economic Psychology, Vol 22 No. 3pp. 377-395.

Clardy, A. (2012), “Organisational reputation: Issues in conceptualization and measurement", Corporate Reputation Review, Vol. 15 No. 4, pp. 285-303.

Carmeli, A. (2005), "Perceived external prestige, affective commitment, and citizenship behaviour", Organization Studies, Vol 26 No.3, pp. 443-464. 
Cheng, J. T., Tracy, J. L. and Henrich, J. (2010), "Pride, personality, and the evolutionary foundations of human social status", Evolution and Human Behavior, Vol. 31 No. 5, pp. 334347.

Chen, Q. and Rogers, S. (2006), "Development of an instrument to measure web site personality", Journal of Interactive Advertising, Vol. 7 No. 1, pp. 4-46.

Churchill, G. A. Jr. (1979), “A paradigm for developing better measures of marketing constructs", Journal of Marketing Research, Vol. 16 No.1, pp 64-73.

Cohen, R. J. (2014), "Brand personification: Introduction and overview," Psychology \& Marketing, Vol. 31 No.1, pp. 1-30.

Connelly, B. L., Certo S. T., Ireland, D. R. and Reutzel, C. R. (2011), "Signalling theory: A review and assessment", Journal of Management, Vol. 37 No.1, pp.39-67.

Cuddy, A. J. C., Fiske S. T. and Glick, P. (2008), "Warmth and competence as universal dimensions of social perception: The Stereotype Content Model and the BIAS map", Advances in Experimental Social Psychology, Vol.40 (December), pp.61-149.

Cuddy, A. J., Fiske, S. T., Kwan, V. S., Glick, P., Demoulin, S., Leyens, J.P., Bond, M. H. , Croizet, J. C. , Ellemers, N. , Sleebos, E. and Htun, T. T. (2009), "Stereotype content model across cultures: Towards universal similarities and some differences", British Journal of Social Psychology, Vol. No.81, pp.1-33.

Das, G.. Datta, B., Guin, K.K. (2012), "Impact of retailer personality on consumerbased retailer equity: An empirical study of retail brands", Asia Pacific Journal of Marketing and Logistics, Vol. 24 Issue: 4, pp.619-639.

Davies, G., Chun, R. da Silva, R. V. and Roper, S. (2001), “The personification metaphor as a measurement approach for corporate reputation", Corporate Reputation Review, Vol.4 No. 2 pp. $113-128$. 
Davies, G., Chun, R. da Silva, R. V. and Roper, S. (2004), “A Corporate Character Scale to assess employee and customer views of organisation reputation", Corporate Reputation Review, Vol.7 No.2, pp. 125-146.

Digman, J. M. (1990), "Personality structure: Emergence of the Five-factor Model”, Annual Review of Psychology, Vol. 41 No. 1, pp. 417-440.

Eastman, J. K., Goldsmith, R. E. and Flynn, L. R. (1999), "Status consumption in consumer behavior: Scale development and validation". Journal of Marketing Theory and Practice, Vol. 7 No. 3, pp. 41-52.

Eisend, M. and Stokburger-Sauer, N. E. (2013), “ Brand personality: A meta-analytic review of antecedents and consequences", Marketing Letters, Vol. 24 No. 3, pp. 205-216.

Ekinci, Y. and Hosany, S. (2006), "Destination personality: An application of brand personality to tourism destinations", Journal of Travel Research, Vol. 45 No.2, pp. 127-139.

Erdem, T. and Swait, J. (1998), "Brand equity as a signalling phenomenon" Journal of Consumer Psychology, Vol. 7 No.2 pp. 131-157.

Fehr, E. and Fischbacher, U. (2003), "The nature of human altruism”, Nature , Vol.425 October 23, pp. 785-791.

Fiske, S. T., Cuddy, A. J. C., Glick, P. and Xu, J. (2002), “A model of (often mixed) stereotype content: competence and warmth respectively follow from perceived status and competition”, Journal of Personality and Social Psychology, Vol. 82 No.6, pp. 878-902.

Fiske, S. T., Cuddy, A. J. C. and Glick, P. (2007), "Universal dimensions of social cognition: warmth and competence", Trends in Cognitive Sciences, Vol. 11 No. 2, pp. 77-83.

Fombrun, C. and Shanley, M. (1990), "What's in a name? Reputation building and corporate strategy", Academy of Management Journal, Vol. 33 No.2, pp. 233-258. 
Fornell, C. and Larcker, D. F. (1981), "Evaluating structural equation models with unobservable variables and measurement error", Journal of Marketing Research, Vol.18 No.1, pp. 39-50.

Geuens, M., Weijters. B. and de Wulf, K. (2009), “A new measure of brand personality”, International Journal of Research in Marketing, Vol. 26 No.2, pp. 97-107.

Griskevicius, V., Tybur, J. M., Sundie, J. M., Cialdini, R. B., Miller, G. F. and Kenrick, D. T. (2007), "Blatant benevolence and conspicuous consumption: When romantic motives elicit strategic costly signals", Journal of Personality and Social Psychology, Vol. 93 No.1 pp. 85-102.

Han, Y. G., Nunes, J. C. and Drèze, X. (2010), "Signalling status with luxury goods: The role of brand prominence", Journal of Marketing, Vol. 74 No.4 pp. 15-30.

Herbst, U. and Merz, M. A. (2011), “The industrial brand personality scale: Building strong business-to-business brands", Industrial Marketing Management, Vol. 40 No.7, pp. 10721081.

Hofstede, A., van Hoof, J., Walenberg, N., and de Jong, M. (2007), “Projective techniques for brand image research: Two personification-based methods explored", Qualitative Market Research: An International Journal, Vol. 10 No. 3pp. 300 - 309.

Hogan, R. and Hogan, J. (2007) Hogan Personality Inventory Manual, $3^{\text {rd }}$ edition,Hogan Assessment Systems, Tulsa, Oklamhoma.

Hosany, S., Ekinci, Y. and Uysal, M. (2006), "Destination image and destination personality: An application of branding theories to tourism places, Journal of Business Research, Vol. 59 No. 5, pp. 638-642.

Huang, H. H,,, Mitchell, V-W. and Rosenaum-Elliott , R. (2012), “Are consumer and brand personalities the same?", Psychology \& Marketing, Vol. 29 No. 5, pp.334-349. 
Iredale, W., van Vugt, M., and Dunbar R. (2008), "Showing off in humans: Male generosity as a mating signal", Evolutionary Psychology, Vol. 6 No. 3, pp. 386-392.

John, O. P. and Srivastava, S. (1999), “The Big Five trait taxonomy: History, measurement, and theoretical perspectives", in Pervin, L. A, and John, O. P. (Eds.), Handbook of Personality: Theory and Research, $2^{\text {nd }}$ Ed., New York: Guilford, pp. 102-138.

Kang, C., Bennett, G. and Peachey, J. W. (2016), "Five dimensions of brand personality traits in sport”, Sport Management Review, Vol.19 No.4, pp. 441-453.

Kassarjian, H. H. (1971), "Personality and consumer behavior: A review”. Journal of Marketing Research, Vol. 8 No.4, pp. 409-18.

Kaplan, M. D., Yurt, O., Guneri, B. and Kurtulus. K. (2010), "Branding places: Applying brand personality concept to cities", European Journal of Marketing, Vol. 44 No.9/10, pp.1286-1304.

Keller, K. L. (1998), Strategic Brand Management, Prentice Hall, New Jersey, pp.320-322.

Kervyn, N., Fiske, S. T. and Malone, C. (2012), "Brands as intentional agents framework: How perceived intentions and ability can map brand perception", Journal of Consumer Psychology, Vol. 22 No.2, pp. 166-176.

King, S. (1973), Developing New Brands, Pitman, London, pp. 11-14.

Kim, S. and Lehto, X. Y. (2012), "Projected and perceived destination brand personalities: The case of South Korea", Journal of Travel Research, Vol. 52 No. 1, pp.117-130.

Krings, F, Sczesny, S. and Kluge, A. (2011), "Stereotypical inferences as mediators of age discrimination: The role of competence and warmth", British Journal of Management, Vol. 22 No.2, pp.187-201.

Markham, V. (1972), Planning the Corporate Reputation, George Allen \& Unwin, London. 
McCrae, R. R. and John, O. P. (1992), “An introduction to the Five Factor Model and its applications", Journal of Personality, Vol.60 No.2, pp.175-215.

McCrae, R. R. and Costa, P. T. Jr. (1997), "Personality trait structure as a human universal", American Psychologist, Vol. 52 No. 5, pp.509-516.

McCrae, R. R. and Allik, J. (2002), "Introduction”, in McCrae, R. R. and Allik, J. (Eds.), The Five-Factor Model of personality across cultures, Kluwer, New York, pp. 1-4.

Milas, G. and Mlačić, B. (2007), "Brand personality and human personality: Findings from ratings of familiar Croatian brands", Journal of Business Research, Vol. 60 No.6, pp. 620626.

Muniz, K. M. and Marchetti, R. Z. (2012), "Brand personality dimensions in the Brazilian context”, BAR-Brazilian Administration Review, Vol. 9 No. 2, pp. 168-188.

Murphy, L., Moscardo, G. and Benckendorff, P. (2007), "Using brand personality to differentiate regional tourism destinations", Journal of Travel Research, Vol. 46 No.1, pp. 514.

Musek, J. (2007) "A general factor of personality: Evidence for the Big One in the Fivefactor Model", Journal of Research in Personality, Vol. 41 No. 6, pp. 213-233.

Nelissen, R. M. A. and Meijers, M. H. C. (2011), "Social benefits of luxury brands as costly signals of wealth and status", Evolution and Human Behavior, Vol. 32 No. 5, pp. 343-355.

Nöth, W. (1988), “The language of commodities: Groundwork for a semiotics of consumer goods", International Journal of Research in Marketing, Vol. 4 No. 3, pp. 173-186.

O’Shaughnessy, J. and O’Shaughnessy, N. J. (2000), “Treating the nation as a brand: Some neglected issues", Journal of Macromarketing, Vol. 20 No. 1, pp. 56-64. 
Osborne, J. and Costello, A. B. (2009), “ Best practices in exploratory factor analysis: Four recommendations for getting the most from your analysis", Pan-Pacific Management Review, Vol. 12 No. 2, pp. 131-146.

Page, G. and Farr, A. (2000), "Do you have an elastic brand?", Advertising Research Foundation Workshop, London.

Poddar, A., Donthu, N. and Wei, Y. (2009), "Web site customer orientations, web site quality, and purchase intentions: The role of web site personality", Journal of Business Research, Vol. 62 No.4, pp. 441-450.

Rao, A. R., Qu, L., and Ruekert, R. W. (1999), "Signaling unobservable product quality through a brand ally", Journal of Marketing Research, Vol. 36 No. 2, pp. 258-268.

Rauschnabel, P.A., Krey, N., Babin, B. J. and Ivens, B. S. (2016), "Brand management in higher education: The University Brand Personality Scale”, Journal of Business Research, Vol. 69 No. 8, pp. 3077-3086.

Rojas-Méndez, J. I., Murphy, S. A. and Papadopoulos, N. (2013a), “The U.S. brand personality: A Sino perspective”, Journal of Business Research, Vol. 66 No.8, pp. 1028 1034.

Rojas-Méndez, J. I., Papadopoulos, N. and Murphy, S. A. (2013b), "Measuring and positioning nation brands: A comparative brand personality approach", Corporate Reputation Review, Vol.16 No.1, pp. 48-65.

Rojas-Méndez, J.I. and Papadopoulos, N, (2012), “Argentine consumers' perceptions of the U.S. brand personality", Latin American Business Review, Vol.13 No.4, pp. 329-345.

Simons, T. L. and Peterson, R. S. (2000), "Task conflict and relationship conflict in top management teams: The pivotal role of intragroup trust", Journal of Applied Psychology, Vol. 85 No.1, pp. 102-111. 
Slaughter, J. E., Zickar, M. J., Highhouse, S. and Mohr, D. C. (2004), "Personality trait inferences about organizations: Development of a measure and assessment of construct validity", Journal of Applied Psychology, Vol. 89 No. 1, pp. 85-102.

Smidts A., Pruyn, A. T. H. and van Riel, C. B. M. (2001), “The impact of employee communication and perceived external prestige on organizational identification", The Academy of Management Journal, Vol.44 No.5, pp. 1051-1062.

Smit, E. G., van den Berge, E. and Franzen, G. (2002), "Brands are just like real people! The development of SWOCC's brand personality scale", in Hansen F. and Christensen, L. B. , (Eds.), Branding and Advertising, Copenhagen Business School Press, Copenhagen, pp. 2243.

Soane, E., Truss, C., Alfes, K., Shantz, A., Rees, C. and Gatenby, M. (2012), "Development and application of a new measure of employee engagement: the ISA engagement scale", Human Resource Development International, Vol. 15 No.5, pp.529-547.

Spence, M. (1973), “Job market signalling”, Quarterly Journal of Economics, Vol. 87, pp. $355-374$.

Sung, Y and Tinkham, S. F. (2005), "Brand personality structures in the United States and Korea: Common and culture-specific factors", Journal of Consumer Psychology, Vol. 15 No. 4, pp. 334-350.

Sung, Y., Choi, S. M., Ahn, H. and Song, Y-A. (2015), "Dimensions of luxury brand personality: Scale development and validation”, Psychology \& Marketing, Vol.32 No.1, pp. 121-132.

Turke, P. W. and Betzig, L. L. (1985), “Those who can do: Wealth status and reproductive success on Infaluk", Ethnology and Sociobiology, Vol. 6 No.2, pp. 79-87.

Vandenabeele, W., Hondeghem, A. and Steen, T. (2004), “The Civil Service as an employer of choice in Belgium", Review of Public Personnel Administration, Vol. 24 No. 4, pp. 319333. 
Venable, B. T., Rose, G. M., Bush, V. D. and Gilbert, F. W. (2005), "The role of brand personality in charitable giving: An assessment and validation", Journal of the Academy of Marketing Science, Vol. 33 No. 3, pp. 295-312.

von Wallpach, S., Voyer, B., Kastanakis,M., and Mühlbacher, H. (2017),’Co-creating stakeholder and brand identities: Introduction to the special issue", Journal of Business Research, Vol. 70, pp. 395-398.

Wang, S., Beatty, S. E. and Foxx, W.(2004), "Signalling the trustworthiness of small online retailers", Journal of Interactive Marketing, Vol. 18 No. 1, pp. 53-69.

Willems, K., Swinnen, G., Janssens, W. and Brengman. M. (2011), "Fashion store personality: Scale development and relation to self-congruity theory", Journal of Global Fashion Marketing, Vol.2 No.2, pp. 55-65.

Yoon, C., Gutchess, A. H., Feinberg, F. and Polk, T. A. (2006), “A functional magnetic resonance imaging study of neural dissociations between brand and person judgments", Journal of Consumer Research, Vol. 33 No.1, pp. 31-40.

Zahavi, A.(1977)," The cost of honesty", Journal of Theoretical Biology, Vol. 67 No.3, pp. 603-605. 
Table (1) The dimensions of entity brand personality in prior work

\begin{tabular}{|l|l|l|l|l|l|l|l|l|l|l|l|l|l|l|l|l|l|l|l|l|l|l|l|l|}
\hline \multicolumn{1}{|c|}{ Dimensions (and typical items) } & 1 & 2 & 3 & 4 & 5 & 6 & 7 & 8 & 9 & 10 & 11 & 12 & 13 & 14 & 15 & 16 & 17 & 18 & 19 & 20 & 21 \\
\hline Sincerity (honest, genuine, cheerful) & $\mathrm{X}$ & $\mathrm{X}$ & $\mathrm{X}$ & & $\mathrm{X}$ & $\mathrm{X}$ & $\mathrm{X}$ & $\mathrm{X}$ & $\mathrm{X}$ & $\mathrm{X}$ & $\mathrm{X}$ & $\mathrm{X}$ & $\mathrm{X}$ & & $\mathrm{X}$ & $\mathrm{X}$ & $?$ & $\mathrm{X}$ & $\mathrm{X}$ & $?$ & $\mathrm{X}$ \\
\hline Competence (reliable, dependable, efficient) & $\mathrm{X}$ & & $\mathrm{X}$ & $\mathrm{X}$ & $\mathrm{X}$ & $\mathrm{X}$ & $\mathrm{X}$ & & $\mathrm{X}$ & $\mathrm{X}$ & $\mathrm{X}$ & & $\mathrm{X}$ & $\mathrm{X}$ & $\mathrm{X}$ & $?$ & $\mathrm{X}$ & & $\mathrm{X}$ & $\mathrm{X}$ & \\
\hline Excitement (daring, imaginative, up-to-date) & $\mathrm{X}$ & $\mathrm{X}$ & $\mathrm{X}$ & $\mathrm{X}$ & $\mathrm{X}$ & $\mathrm{X}$ & $\mathrm{X}$ & & $\mathrm{X}$ & $\mathrm{X}$ & $\mathrm{X}$ & $?$ & $\mathrm{X}$ & $\mathrm{X}$ & $\mathrm{X}$ & $?$ & $\mathrm{X}$ & $\mathrm{X}$ & $\mathrm{X}$ & $\mathrm{X}$ & $\mathrm{X}$ \\
\hline Sophistication (glamorous, charming, romantic) & $\mathrm{X}$ & $\mathrm{X}$ & $\mathrm{X}$ & & $\mathrm{X}$ & $?$ & $\mathrm{X}$ & $\mathrm{X}$ & & $\mathrm{X}$ & & $?$ & & & & $\mathrm{X}$ & $\mathrm{X}$ & & & $\mathrm{X}$ & \\
\hline Ruggedness (tough, strong, rugged) & $\mathrm{X}$ & & & $\mathrm{X}$ & $?$ & $?$ & & $\mathrm{X}$ & & & & & & $?$ & & & & & & & \\
\hline Ruthlessness (controlling, aggressive) & & & & & $\mathrm{X}$ & & & & $\mathrm{X}$ & $?$ & & $?$ & & $\mathrm{X}$ & & & & $?$ & & & \\
\hline Thrift (poor, sloppy, low class) & & $\mathrm{X}$ & & & & $\mathrm{X}$ & & & & & & & & & & & & & & & \\
\hline Peacefulness (gentle, mild, peaceful) & & $\mathrm{X}$ & $\mathrm{X}$ & $\mathrm{X}$ & & & & & & & & & & $\mathrm{X}$ & & & & & & & $\mathrm{X}$ \\
\hline Unpleasant (annoying, irritating, outmoded) & & & & $\mathrm{X}$ & & & $\mathrm{X}$ & & & & & & $\mathrm{X}$ & & & & & & & \\
\hline Simplicity (ordinary, simple) & & & & & $?$ & & & & & & & $\mathrm{X}$ & & & & & & & & & \\
\hline Sensitivity (delicate, sensitive, romantic) & & & & & & & & $?$ & & & & & & & & & $\mathrm{X}$ & & & & \\
\hline Conformity (religious, spiritual, traditionalist) & & & & & & & & & & $\mathrm{X}$ & & & & & & & & & & & \\
\hline Prestige (reputable, successful) & & & & & & & & & & & & & & & & & & & $\mathrm{X}$ & $\mathrm{X}$ & $\mathrm{X}$ \\
\hline Cosmopolitan (international, cosmopolitan) & & & & & & & & & & & & & & & & & & & $\mathrm{X}$ & & \\
\hline Materialism (selfish, materialistic, pretentious) & & & & & & & & & & & & & & & & & & & & $\mathrm{X}$ & \\
\hline Conspicuousness (special, extravagant striking) & & & & & & & & & & & & & & & & & & & & & X \\
\hline
\end{tabular}

$\mathbf{X}$ indicates that the dimension is apparent in the study, ? that it may be present and a blank that it was not present

Studies: 1 Aaker (1997); 2 Aaker et al. (2001); 3 Aaker et al. (2001); 4 Smit et al. 2002; 5 Davies et al. (2004); 6 Slaughter et al. (2004); 7 d'Astous and Levesque (2003); 8 Venable et al. (2005); 9 Bosnjak et al. (2007); 10 d'Astous and Boujbel (2007); 11 Milas and Mlaĉić (2007); 12 Geuens et al. (2009); 13 Chen and Rodgers (2006); 14 Kaplan et al. (2010); 15 Herbst and Merz (2011); 16 Das et al. (2012); 17 Muniz and Marchetti (2012); 18 Rojas-Méndez et al. (2013); 19 Rauschnabel et al. (2016); 20 Sung et al. (2015); 21 Willems et al (2011). 
Table (2) The relative ability of Sincerity, Competence and Status to Predict 4 Outcomes

\begin{tabular}{|l|l|l|l|l|}
\hline DV & Sincerity & Competence & Status & Adjusted $\mathrm{R}^{2}$ \\
\hline $\begin{array}{l}\text { Product Purchase } \\
\text { Intentions }\end{array}$ & $13.6(.000)$ & $19.5(.000)$ & $2.06(.039)$ & $.234(.000)$ \\
\hline Travel Intentions & $19.9(.000)$ & $18.8(.000)$ & $5.13(.000)$ & $.306(.000)$ \\
\hline $\begin{array}{l}\text { Intention to } \\
\text { develop ties }\end{array}$ & $22.9(.000)$ & $13.9(.003)$ & $7.78(.000)$ & $.311(.000)$ \\
\hline Overall Attitude & $36.5(.000)$ & $13.0(.000)$ & $5.71(.000)$ & $.425(.000)$ \\
\hline
\end{tabular}

$\mathrm{t}$ values are given, with significance in parentheses.

Table (3) The relative ability of Sincerity, Competence and Status to Predict 3 Outcomes

\begin{tabular}{|l|l|l|l|l|}
\hline DV & Sincerity & Competence & Status & Adjusted $\mathrm{R}^{2}$ \\
\hline Satisfaction & $2.80(.006)$ & $4.46(.000)$ & $0.740(.460)$ & $.487(.000)$ \\
\hline Engagement & $3.16(.002)$ & $2.96(.004)$ & $0.297(.770)$ & $.407(.000)$ \\
\hline $\begin{array}{l}\text { Self-image } \\
\text { congruence }\end{array}$ & $5.01(.000)$ & $3.05(.003)$ & $3.83(.000)$ & $.637(.000)$ \\
\hline
\end{tabular}

$\mathrm{t}$ values are given, with significance in parentheses. 


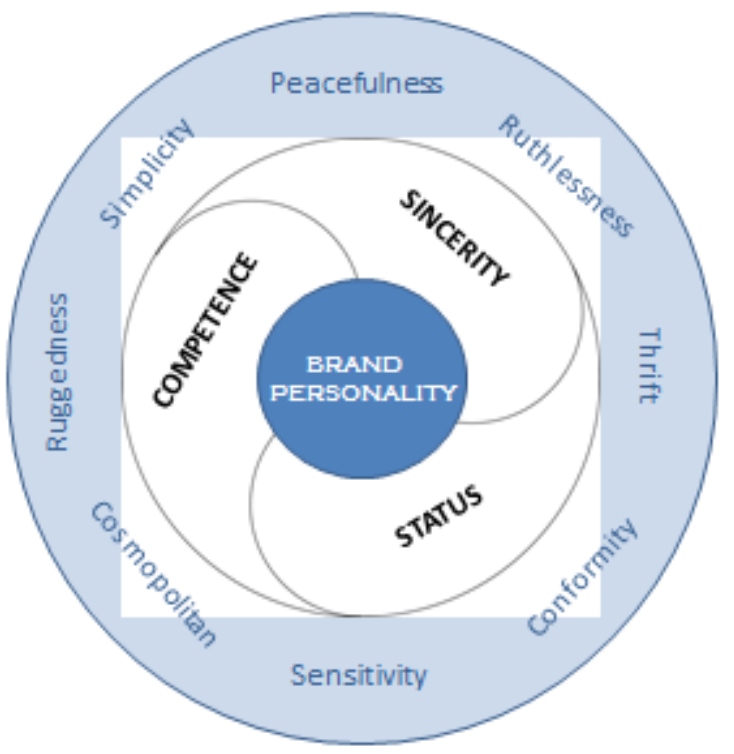

Figure 1 A Model of Brand Personality 